\title{
Anemia in HIV/AIDS Patients on Antiretroviral Treatment at Ayder Specialized Hospital, Mekele, Ethiopia: A Case-Control Study
}

This article was published in the following Dove Press journal: Journal of Blood Medicine

\author{
Yemane Berhane' \\ Diresibachew Haile ${ }^{2}$ \\ Tesfaye Tolessa $\mathbb{D D}^{2}$ \\ 'Department of Biomedical Science, \\ College of Medicine and Health Science, \\ Adigrat University, Adigrat, Northern \\ Ethiopia, Ethiopia; ${ }^{2}$ Department of \\ Medical Physiology, School of Medicine, \\ College of Medicine and Health Science, \\ Addis Ababa University, Addis Ababa, \\ Ethiopia
}

Background: Human immunodeficiency virus and anemia are the major public health problems in Sub-Sahara Africa. Untreated anemia is associated with rapid progression and poor prognosis of the disease in HIV. This study was aimed at determining the magnitude, severity and associated factors of anemia among HIV infected patients taking zidovudine and tenofovir-containing first-line HAART in Ayder Comprehensive Specialized Hospital, Mekele, Ethiopia.

Methods: A case-control study was conducted from February to August 2019 using both convenient and quota sampling methods. Anemia is defined as hemoglobin value below $13 \mathrm{~g} /$ $\mathrm{dl}$ for male and below $12 \mathrm{~g} / \mathrm{dl}$ for female. Sociodemographic and clinical characteristics were assessed using a structured questionnaire, medical records, electronic weighing scale, adult height board, automated hematology analyzer (Sysmex XT-4000i), and Becton Dickinson's FACS caliber flow cytometer. Descriptive statistics, tables, graphs, Student's $t$-test and 1 logistic regression were used to analyze the data.

Results: About one-third (33.5\%) of study participants were found to be anemic (ZDV: 20.3\%; TDF: $13.2 \%$, and $\mathrm{p}<0.05$ ). Among these anemic cases, the majority was found to have mild, and the remaining was moderate types. The most common form was normocytic-normochromic anemia (46.5\%). Cotrimoxazole prophylaxis, poor adherence, advanced AIDS stage at baseline and underweight at baseline were the factors associated with anemia in patients taking zidovudine-containing regimen $(p<0.05)$. Advanced stage at baseline, cotrimoxazole prophylaxis, poor adherence status and lack of regular income were significantly associated with anemia in patients taking tenofovir-containing regimen $(\mathrm{p}<0.05)$.

Conclusion: We find that the prevalence of anemia was significantly higher among patients taking ZDV-containing regimen. But different risk factors for anemia had been identified among ZDV-containing regimen, showing that appropriate follow-up, nutritional supplementation, continuous evaluation of patients on cotrimoxazole intake can reduce the risks of anemia in both types of regimens.

Keywords: HIV/AIDS, tenofovir, zidovudine, anemia, Ethiopia

\section{Background}

Cytopenia is a common complication of the human immunodeficiency virus (HIV) that can result from a defect in the development of bone marrow production, increased peripheral blood loss or blood cell destruction. Anemia is the most common cytopenia, which can occur in up to $95 \%$ of HIV patients during their disease course. ${ }^{1}$
Correspondence: Yemane Berhane Department of Biomedical Science, College of Medicine and Health Science, Adigrat University, P. O. Box 50, Adigrat, Northern Ethiopia, Ethiopa

Email yemaneberhane04I@gmail.com 
According to the World Health Organization (WHO) anemia is defined as hemoglobin $(\mathrm{Hb})$ concentration below $12.0 \mathrm{~g} / \mathrm{dL}$ in women and below $13.0 \mathrm{~g} / \mathrm{dL}$ in men. ${ }^{2}$ Anemia is a multifactorial condition that may result from several pathophysiological mechanisms. It is a global public health problem affecting both developing and developed countries at all ages. Globally, it affects 1.62 billion people, which corresponds to $24.8 \%$ of the population. ${ }^{4}$

During HIV-infection the prevalence of anemia varies by demographic characteristics of the population and stage of the disease. It is generally higher in advanced HIV infection; among women, infants, and children; and in developing countries. ${ }^{5}$ In HIV infected patients anemia can have serious complications ranging from functional and quality-of-life decrements to disease progression and decreased survival. Worldwide iron deficiency anemia is the commonest of all in HIV patients on highly active antiretroviral therapy (HAART), in developed countries about $35 \%$ of patients on HAART develop anemia. ${ }^{6}$ Regimens comprising nucleotide reverse transcriptase inhibitors (NRTI); (TDF + 3TC) and integrase inhibitor dolutegravir (DTG) as the preferred choices or NRTI $(\mathrm{ZDV}+3 \mathrm{TC})$ with DTG or Efavirenz (EFV) as an alternative regimen are currently in use for adults in Ethiopia. ${ }^{7}$

Factors causing anemia in HIV-infected individuals can be categorized into three main classes. These are decreased red blood cell (RBC) production in the bone marrow, increased RBC destruction, and ineffective RBC production due to nutritional deficiencies. ${ }^{8}$ Medication (ie, zidovudine, cotrimoxazole, amphoteric B) induced anemia with a normal iron label and normal to high mean corpuscle volume (MCV) develops within the first week of HAART. Drug therapy is the most common cause of megaloblastic or macrocytic anemia in HIV infected patients. Cotrimoxazole can also cause megaloblastic anemia because of folate antagonism, especially in patients with compromised nutritional status. ${ }^{9}$

A study of serum immunoreactive erythropoietin in HIV infected patients across the spectrum of disease stages revealed that levels of the hormone failed to rise commensurately with increasing anemia. This suggests that insufficient erythropoietin levels may be one cause of anemia in HIV patients. ${ }^{9}$ Reports from Indonesia showed anemia is less common in patients taking HAART $(7.4 \%)$, while the use of ZDV is associated with anemia (20.3\%). They also recorded $14.3 \%$ mild, $1.9 \%$ moderate, and no patients with severe anemia. ${ }^{10}$ A cross-sectional study conducted in Debretabor Hospital, Ethiopia revealed an overall anemia prevalence of $23 \%$. Being HAART naïve, having a treatment history with anti-tuberculosis medications, taking ZDV containing HAART regimen, and having CD4 counts below 200 cells $/ \mu \mathrm{L}$ were associated with the occurrence of anemia among adult HIV patients. ${ }^{11}$

A comparative cross-sectional study in Jimma, Ethiopia reported the overall prevalence of anemia involving 54 HIV patients is $23.1 \%$, with anemia seen in $16.2 \%$ of HAART experienced and $29.9 \%$ of HAART naive participants. The study reported; among the total cases $1.9 \%$, $25.9 \%$, and $72.2 \%$ were with severe, moderate, and mild anemia respectively. In their report type of HAART regimen and duration of HAART are significantly associated with anemia. ${ }^{12}$ Another quantitative cross-sectional study conducted in Jimma, Ethiopia reported anemia was the most common cytopenia with 43.1\% (56/130) among patients on HAART follow-up. ${ }^{13}$

Given this background, the current study aimed to describe the magnitude of anemia and its predictors along with the severity and morphological features among peoples living with HIV/AIDS taking different combined first-line antiretroviral drugs. Furthermore, this study will provide comparative information on the characteristics of anemia among patients who took ZDV and TDF containing HAART. This study will further contribute to another input for the health professionals in the assessment and care of the difference in the hematologic profiles of HIV-infected patients taking ZDV and TDF containing HAART.

\section{Methods}

This study was conducted in Ayder Comprehensive Specialized Hospital located in Mekele city, Northern Ethiopia from February to August 2019. During the data collection period, a total of 1478 adult HIV patients were on regular HAART follow-up. An unmatched case-control study was conducted by considering patients on zidovudine (ZDV) containing HAART as cases and those on tenofovir (TDF) containing HAART as a control group. We considered them as cases and controls, because of the previous reports from other study areas, and clinical practitioners in our country consider ZDV containing regimen as a main risk factor for anemia but not TDF containing regimen. But no detail data was available on the prevalence and possible risk factors in both regimen types.

HIV positive individuals aged 18 years and above, who were on first-line HAART for at least six months with complete baseline hematologic profile and CD4 count 
were included in the study. HIV/AIDS patients who had a history of blood transfusion in the last one year, chronic disease (ie, renal failure, chronic liver diseases, stomach ulcer, and hematologic disorders), pregnant and lactating women, who had severe anemia before the start of HAART, and those on stage three or four AIDS patients during the study period were excluded from the study. All adult HIV/AIDS patients who met the inclusion criteria voluntarily consented to participate in the study, and who were recruited to the first line HAART regimen on regular follow-up during the study period, were the study population.

This study considered $\mathrm{Hb}$ value below $8.0 \mathrm{~g} / \mathrm{dl}$ as severe anemia, 8.0-10.9 g/dl moderate, 11-12.9 $\mathrm{g} / \mathrm{dl}$ for male, and 11-11.9 $\mathrm{g} / \mathrm{dl}$ for the female as mild anemia. Morphologically, anemia was classified as microcytic (mean corpuscle volume, MCV below $80 \mathrm{fl}$ ), normocytic (MCV: 80-100fl), macrocytic (MCV above 100fl), hypochromic (mean cell hemoglobin concentration, MCHC below 31\%), and normochromic (MCHC: 31-36). ${ }^{3,14}$

The sample size was calculated using STAT CALC Epi-info based on the assumptions: two-sided confidence level at 95\%, a standard margin of error (power of 90\%), and 1:1 ratio of cases and controls. The prevalence of anemia for $\mathrm{ZDV}$ and $\mathrm{TDF}$ containing regimen was $57.86 \%$ and $34.95 \%$ respectively, as per a study conducted in Tanzania. ${ }^{15}$ Accordingly, a total of 212 participants were included in the study. Individuals were selected using convenience and quota sampling whereby the data collectors screened eligible individuals during their arrival to the clinic for their monthly follow-up, and fulfilled the data until the required sample was completed with equal proportion for cases and controls.

A structured pretested questionnaire containing sociodemographic and clinical characteristics (stage of disease, cotrimoxazole prophylaxis therapy [CPT] use, adherence status, cluster of differentiation 4 [CD4] count, baseline clinical profiles) to be captured at baseline and following HAART initiation were used to collect the data. Blood samples were collected by trained laboratory technicians for complete blood count (CBC) and CD4 analysis. Automated hematology analyzer (Sysmex XT- 4000i) and Becton Dickinson's (BD) FACS count were used for this purpose.

The data collectors were trained on operational procedures of each aspect of the study and the reproducibility of the data. The weight scale was calibrated before each measurement. The performance of the automated hematology analyzer machine was controlled externally by running quality control samples according to the laboratory's protocol. Collected data were manually checked for its completeness, and entered into the SPSS ${ }^{\text {TM }}$ version 24.0 software package for statistical analysis. Descriptive statistics were used to determine the prevalence of anemia and other hematologic profiles. Continuous variables were checked for distribution using normal curves. Paired and independent sample t-tests were used to compare the mean and means among different treatment groups respectively. Bivariate and multivariate logistic regression analysis was used to determine the effect of various factors and to deal with the effect of confounding variables respectively. Statistical significance was considered at a p-value less than 0.05 and a $95 \%$ confidence interval.

\section{Result \\ General Clinical Characteristics}

A total of 212 study participants over two groups (106 ZDV and 106 TDF group) were included in this study. Women were slightly higher in number $(54.7 \%$ women and $45.3 \%$ male). The mean age and standard deviation (SD) of all participants by treatment group were $41.1 \pm$ 10.99 and $42.25 \pm 10.22$ years for ZDV and TDF respectively. The majority $(59.4 \%, 65.1 \%, \mathrm{n}=132)$ of the study participants were between 30-49 years in the ZDV and TDF groups respectively. The two study groups were comparable in most of the sociodemographic characteristics $(\mathrm{p}>0.05)$ (Table 1).

Nearly three-quarters of the participants in both groups were in the advanced AIDS stage at the time of enrolment (pre-HAART) (Table 2). The mean duration of HAART intake was $58 \pm 26$ months for the ZDV group and $63 \pm 36$ months for the TDF group with the range from 7 to 139 months. Following HAART initiation, $94.8 \%$, of the study participants in both study groups had a CD4 count above 200 cells $/ \mathrm{mm} .{ }^{3}$ The other clinical characteristics of the participants based on the regimen types are described in Table 3 .

In both study groups, paired sample $t$-test analysis revealed significant $(p<0.05)$ increment of mean CD4 count following HAART initiation. Independent $t$-test statistics revealed the mean $\mathrm{Hb}$ value was significantly higher $(\mathrm{p}<0.05)$ among TDF (control) groups.

\section{Prevalence of Anemia}

This study showed anemia prevalence before the start of HAART was $37.7 \%$ (ZDV group: $12.7 \%$, TDF group: 
Table I Sociodemographic Characteristics of the Participants on HAART in ACSH, Mekele, Ethiopia, 2019

\begin{tabular}{|c|c|c|c|c|c|}
\hline \multirow[t]{2}{*}{ Variables } & \multicolumn{2}{|l|}{$\begin{array}{l}\text { ZDV Group } \\
(N=106)\end{array}$} & \multicolumn{2}{|c|}{$\begin{array}{l}\text { TDF Group } \\
(N=106)\end{array}$} & \multirow[t]{2}{*}{ P-value } \\
\hline & Frequency & $\begin{array}{l}\text { Valid } \\
\%\end{array}$ & Frequency & $\begin{array}{l}\text { Valid } \\
\%\end{array}$ & \\
\hline \multicolumn{6}{|l|}{ Sex } \\
\hline Male & 47 & 44.30 & 49 & 46.20 & 0.783 \\
\hline Female & 59 & 55.70 & 57 & 53.80 & \\
\hline \multicolumn{6}{|l|}{ Regular income } \\
\hline No & 54 & 50.90 & 46 & 43.40 & 0.271 \\
\hline Yes & 52 & 49.10 & 60 & 56.60 & \\
\hline \multicolumn{6}{|l|}{ Participants age } \\
\hline $20-29$ & 21 & 19.80 & 12 & 11.30 & 0.549 \\
\hline $30-39$ & 30 & 28.30 & 34 & 32.10 & \\
\hline $40-49$ & 33 & 31.10 & 35 & 33.00 & \\
\hline $50-59$ & 14 & 13.20 & 17 & 16.00 & \\
\hline $60-69$ & 8 & 7.50 & 8 & 7.50 & \\
\hline \multicolumn{6}{|l|}{$\begin{array}{l}\text { Educational } \\
\text { status }\end{array}$} \\
\hline $\begin{array}{l}\text { Unable to } \\
\text { read/write }\end{array}$ & 14 & 13.20 & 22 & 20.80 & 0.432 \\
\hline Elementary & 41 & 38.70 & 40 & 37.70 & \\
\hline High school & 29 & 27.40 & 22 & 20.80 & \\
\hline $\begin{array}{l}\text { Diploma and } \\
\text { above }\end{array}$ & 22 & 20.80 & 22 & 20.80 & \\
\hline \multicolumn{6}{|l|}{ Religion } \\
\hline Orthodox & 94 & 88.70 & 95 & 89.60 & 0.825 \\
\hline Muslims & 12 & 11.30 & 11 & 10.40 & \\
\hline \multicolumn{6}{|l|}{ Residence } \\
\hline Rural & 10 & 9.40 & 14 & 13.20 & 0.386 \\
\hline Urban & 96 & 90.60 & 92 & 86.80 & \\
\hline
\end{tabular}

Abbreviations: ZDV, zidovudine; TDF, tenofovir.

25\%). Following HAART initiation around one-third $(33.5 \%)$ of the patients were found to be anemic. A total of $20.3 \%$ of the patients with anemia received ZDV containing regimen. ZDV containing regimen was significantly associated with anemia ( $<<0.05,95 \%$; CI: 1.064 , 3.397). Binary logistic regression analysis revealed the odds of being anemic doubles among individuals taking ZDV containing regimen (OR: 1.90).

\section{Characteristics and Determinants of}

\section{Anemia}

Among the total (33.5\%) anemic cases, the majorities were found to have mild anemia and the remaining moderate anemia; meanwhile, we found no case of severe anemia in this study (Figure 1). We found that normocytic-
Table 2 Baseline Clinical Characteristics of HIV Positive Patients in $\mathrm{ACSH}$, Mekele, Ethiopia, 2019

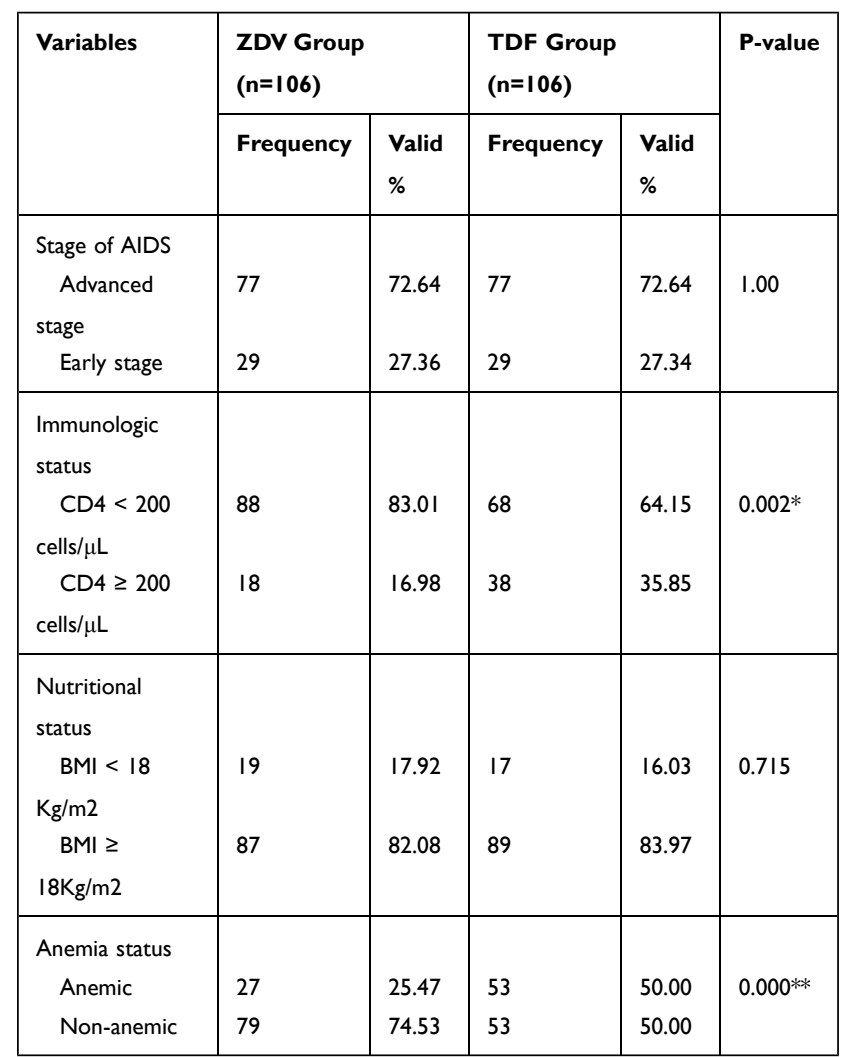

Notes: ${ }^{*} \mathrm{p}<0.05 ;{ }^{*} \mathrm{p}<0.01$.

Abbreviations: BMI, body mass index; TDF, tenofovir; ZDV, zidovudine.

normochromic anemia was the most common in both groups $(46.5 \%)$, followed by macrocytic-normochromic anemia accounting for $29.8 \%$ of the cases (Figure 2).

Multivariate analysis revealed; advanced AIDS stage at enrolment to HAART (AOR: 5.75, $\mathrm{p}<0.05$ ), undernutrition (AOR: 6.60, p<0.05), CPT (AOR: 7.59, $\mathrm{p}<0.01$ ), and poor adherence (AOR: 7.22, $\mathrm{p}<0.05$ ) were the significant predictors of anemia among the ZDV group. On the other hand; absence of regular income (AOR: 4.97, $\mathrm{p}<0.01$ ), CPT (AOR: 4.88, $\mathrm{p}<0.01$ ), and poor adherence (AOR: $8.09, \mathrm{p}<0.05)$ were the significant predictors of anemia among the TDF group (Table 4).

\section{Discussion}

This study showed anemia prevalence of $37.7 \%$ (80/212) at pre-HAART initiation (ZDV group: $12.7 \%$, TDF group: $25 \%)$. The higher prevalence of anemia among the TDF group at baseline (pre-HAART) was in line with the national HIV/AIDS treatment guideline which recommends initiation of TDF containing regimen to patients with lower $\mathrm{Hb}$ concentration. ${ }^{16}$ 
Table 3 Clinical Characteristics of HIV Positive Patients on HAART in ACSH, Mekele, Ethiopia, 2019

\begin{tabular}{|c|c|c|c|c|c|}
\hline \multirow[t]{2}{*}{ Variables } & \multicolumn{2}{|l|}{$\begin{array}{l}\text { ZDV Group } \\
(\mathrm{N}=106)\end{array}$} & \multicolumn{2}{|c|}{$\begin{array}{l}\text { TDF Group } \\
(N=106)\end{array}$} & \multirow[t]{2}{*}{ P-value } \\
\hline & Frequency & $\begin{array}{l}\text { Valid } \\
\%\end{array}$ & Frequency & $\begin{array}{l}\text { Valid } \\
\%\end{array}$ & \\
\hline \multicolumn{6}{|l|}{$\begin{array}{l}\text { WHO clinical } \\
\text { stage }\end{array}$} \\
\hline Stage I & 96 & 90.60 & 98 & 92.50 & 0.623 \\
\hline Stage2 & 10 & 9.60 & 8 & 7.50 & \\
\hline \multicolumn{6}{|l|}{ Adherence } \\
\hline Poor/fair & 21 & 19.80 & 7 & 6.60 & $0.007^{* *}$ \\
\hline Good & 85 & 80.20 & 99 & 93.40 & \\
\hline \multicolumn{6}{|l|}{$\begin{array}{l}\text { Current } \\
\text { isoniazid } \\
\text { prophylaxis (IPT) }\end{array}$} \\
\hline Yes & 34 & 32.10 & 25 & 23.60 & 0.169 \\
\hline No & 72 & 67.90 & 81 & 76.40 & \\
\hline \multicolumn{6}{|l|}{ Drug addiction } \\
\hline Yes & 16 & 15.00 & 18 & 16.98 & 0.708 \\
\hline No & 90 & 85.00 & 88 & 83.02 & \\
\hline \multicolumn{6}{|l|}{$\begin{array}{l}\text { Cotrimoxazole } \\
\text { prophylaxis }\end{array}$} \\
\hline Yes & 38 & 35.80 & 39 & 36.80 & 0.886 \\
\hline No & 68 & 64.20 & 67 & 63.20 & \\
\hline \multicolumn{6}{|l|}{ Anemia status } \\
\hline Anemic & 43 & 40.5 & 28 & 26.4 & $0.029 *$ \\
\hline Non-anemic & 63 & 59.5 & 78 & 73.5 & \\
\hline \multicolumn{6}{|l|}{ Regimen change } \\
\hline Yes & 1 & 0.90 & 4 & 3.80 & 0.175 \\
\hline No & 105 & 99.10 & 102 & 96.20 & \\
\hline
\end{tabular}

Note: ${ }^{*} \mathrm{p}<0.05 ;{ }^{*} \mathrm{p}<0.01$.

Abbreviations: TDF, tenofovir; ZDV, zidovudine.

Following HAART initiation, the prevalence of anemia was found to be $33.5 \%$ (ZDV group: $20.30 \%$, TDF group: $13.2 \%$ and $\mathrm{P}<0.05$ ). This decrement in prevalence is in line with several studies. ${ }^{13,17-19}$ However; it is somewhat higher than a previous finding in Ethiopia, ${ }^{20}$ which reported $25 \%$ anemia prevalence following six months HAART. Variations in prevalence among these two studies could be due to differences in study design, sociodemographic characteristics, duration of HAART follow-up, and cut-off values used to define anemia status. One plausible explanation for the reduction in anemia after initiation of treatment is that HAART can suppress HIV, a virus which is known to directly affect the bone marrow; therefore, by suppressing the viral load could prevent anemia. ${ }^{16}$
This study found that anemia is significantly associated with ZDV containing HAART regimen, and it doubles the risk compared to the TDF based regimen. This finding is in agreement with various studies. ${ }^{15,21,22}$ However, it is in contrast with the findings from a previous study in Jimma, Ethiopia, ${ }^{11}$ which reported no significant difference in the prevalence of anemia and HAART regimen type. The possible explanation for this variance could be that the present study used only a TDF containing regimen to compare with ZDV containing regimen, unlike the Jimmabased studies inclusion of all non-ZDV containing regimens to compare with the ZDV containing regimen. Several hematologic toxicities (ie, neutropenia, anemia, thrombocytopenia, and splenomegaly) had been reported among patients who took ZDV containing regimen. ${ }^{23}$

Among the total anemic cases identified in our study, the majority was found to have mild anemia with the remainders moderate and no cases of severe anemia. This finding mirror a study conducted in Debretabor, Ethiopia, ${ }^{24}$ which reported mild anemia (27.7\%), and moderate anemia $(6.3 \%)$ with no finding of severe anemia. The absence of severe anemia in the present finding might be related to the exclusion of HIV patients in an advanced AIDS stage and patients on second-line HAART treatment during the study period.

In the present study, normocytic-normochromic anemia was the dominant finding. This is consistent with previous studies conducted in Ethiopia, ${ }^{17,18}$ and India. ${ }^{25}$ The possible explanation could be the effect of infections (HIV itself), autoimmune diseases, malnutrition, and malignancies can cause anemia without affecting the size of RBC, and the hemoglobin content. HIV infection, the medications (HAART and CPT), aplastic anemia, and related bone marrow failure state can be associated with red marrow aplasia. This, in turn, can cause selective hypoplasia of the erythroid marrow without loss of megakaryocytes and myeloid precursor cells. ${ }^{26}$

In patients taking ZDV containing regimen anemia was independently predicted by the; advanced AIDS stage at baseline, advanced baseline immune suppression, cotrimoxazole prophylaxis (CPT) intake, poor adherence status, and undernutrition at baseline. This finding is in agreement with the study conducted in Thailand, ${ }^{27}$ which reported, anemia was independently predicted by low baseline CD4 count, low BMI, and advanced AIDS stage at enrolment. The possible explanation for this association may be that HIV patients with low CD4 count are known to be at risk of multiple opportunistic infections, which are 


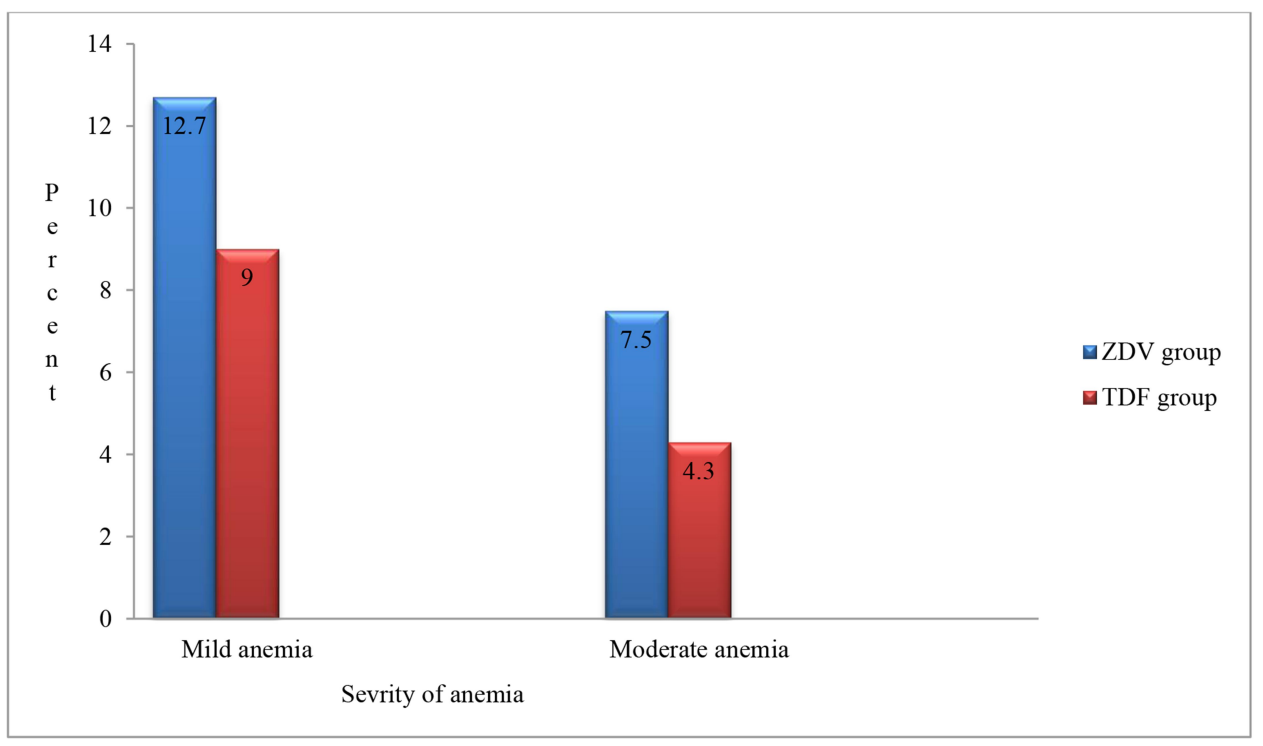

Figure I Percentage of the severity of anemia among patients on ZDV and TDF-containing HAART in ACSH, Mekele, Ethiopia, 2019.

known to cause anemia. Furthermore, such patients are also likely to have high HIV viral load which could lead to viral infiltration of the bone marrow and erythropoietin dysfunction subsequently causing anemia. ${ }^{28}$

The association of CPT with anemia is in accordance with the report from Ethiopia ${ }^{13}$ and Uganda. ${ }^{29}$ WHO recommends continuing CPT until the patient is clinically stable on HAART, with evidence of immune recovery and virologic suppression. ${ }^{30}$ One possible explanation for CPT's association with anemia could be that trimethoprim is a weak inhibitor of dihydrofolate reductase which can inhibit folic acid metabolism, and, in high doses, it has been implicated in megaloblastic changes, particularly in patients who are not on folate supplementation. ${ }^{31}$ Recently other alternatives to CPT such as clindamycin, atovaquone and dapsone are being offered, especially in those with hematological toxicities from cotrimoxazole therapy. ${ }^{30}$

In recipients of TDF containing regimen, anemia was significantly predicted by; rural residence, absence of regular income, CPT intake, and poor adherence status. In line with the present study, Demographic and Health Surveys from 32 countries $^{32}$ reported low income is significantly associated

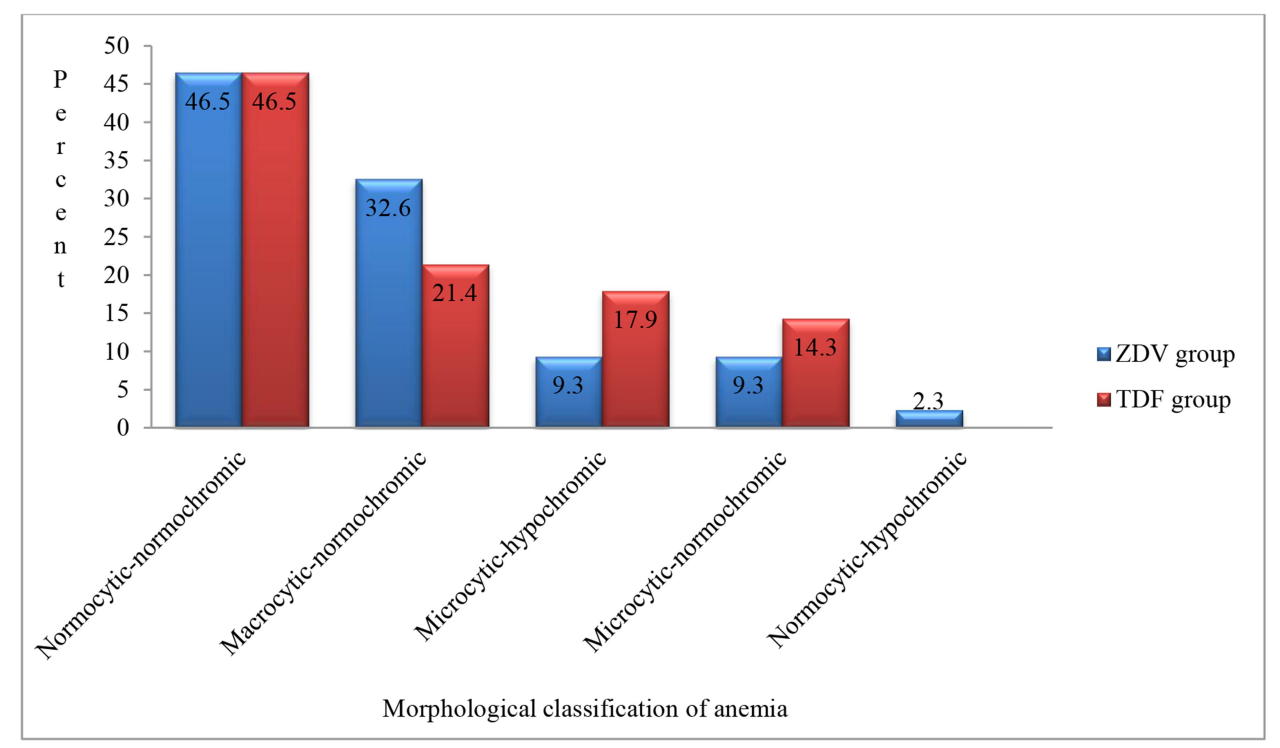

Figure 2 Percentage of morphological characteristics of anemia among patients on ZDV and TDF-containing HAART in ACSH, Mekele, Ethiopia, 20 I9. 
Table 4 Multiple Logistic Regression Analysis for the Predictors of Anemia Among HIV Patients on HAART in ACSH, Mekele, Ethiopia, 2019

\begin{tabular}{|c|c|c|c|c|c|c|}
\hline \multirow[t]{2}{*}{ Categories } & \multicolumn{3}{|c|}{ ZDV Group $(N=106)$} & \multicolumn{3}{|c|}{ TDF Group $(N=106)$} \\
\hline & P-value & COR & AOR $(95 \% \mathrm{Cl})$ & P-value & COR & AOR $(95 \% \mathrm{Cl})$ \\
\hline Pre-HAART Advanced AIDS & $0.025^{*}$ & 2.76 & $5.75(1.24-26.50)$ & 0.919 & 1.53 & $0.94(0.28-3.16)$ \\
\hline CTP intake & $0.003 * *$ & 7.97 & $7.59(2.03-28.39)$ & $0.005^{* *}$ & 4.88 & $5.16(1.63-16.31)$ \\
\hline Poor adherence & $0.014 *$ & 3.86 & $7.22(1.48-35.11)$ & $0.030 *$ & 8.26 & $8.09(1.22-53.54)$ \\
\hline Rural residence & 0.602 & 2.39 & $1.55(0.29-8.17)$ & 0.062 & 3.38 & $4.76(0.92-24.50)$ \\
\hline Absence of regular income & 0.905 & 2.65 & $0.94(0.30-2.87)$ & $0.009 * *$ & 3.21 & $4.97(1.48-16.67)$ \\
\hline Pre-HAART CD4 $<200$ celle $/ \mu \mathrm{L}$ & 0.350 & 4.16 & $2.25(0.40-12.43)$ & 0.405 & 1.24 & $0.60(0.18-1.98)$ \\
\hline Post-HAART undernutrition & 0.573 & 1.81 & $1.65(0.29-9.35)$ & 0.063 & 1.12 & $3.83(0.93-15.83)$ \\
\hline Pre-HAART undernutrition & $0.027 *$ & 5.66 & $6.60(1.24-35.04)$ & 0.881 & 1.24 & $0.89(0.19-4.03)$ \\
\hline
\end{tabular}

Notes: ${ }^{*} \mathrm{p}<0.05,{ }^{* *} \mathrm{p}<0.01$ for the multivariate analysis.

Abbreviations: AOR, adjusted odds ratio; COR, crude odds ratio; $\mathrm{Cl}$, confidence interval; ZDV, zidovudine; TDF, tenofovir; CPT, cotrimoxazole prophylaxis therapy; BMI, body mass index.

with anemia. A report from Jimma, Ethiopia ${ }^{12}$ revealed rural residence as a significant predictor for anemia among HIV positive patients. The possible explanation could be that rural residence and absence of regular income are usually associated with the inaccessibility of adequate and timely health service, regular checkup and counseling on iron supplementation, food fortification for optimal nutrition intake, and anthelminthic therapies. ${ }^{33}$

\section{Conclusion}

Anemia is significantly higher among patients on ZDV containing regimen. Different associated factors of anemia were identified in both study groups. The result of this study showed that anemia remains a public health concern in this cohort of HIV infected adults taking different HAART regimens in the study area.

\section{Abbreviations}

AIDS, acquired immunodeficiency syndrome; AOR, adjusted odds ratio; ART, antiretroviral therapy; BMI, body mass index; $\mathrm{CBC}$, complete blood count; CD4, cluster of differentiation 4; CPT, cotrimoxazole prophylaxis therapy; COR, crude odds ratio; HAART, highly active antiretroviral therapy; HIV, human immunodeficiency virus; OI, opportunistic infections; SSA, Sub-Sahara Africa; TDF, tenofovir disoproxil fumarate; ZDV, zidovudine.

\section{Data Sharing Statement}

The datasets used and/or analyzed during the current study are available from the corresponding author on reasonable request.

\section{Ethical Approval and Consent to Participate}

The study was conducted after an ethical letter was obtained from the Research and Ethical Review Committee of the Department of Medical Physiology, Addis Ababa University, Ethiopia. The proposal was further evaluated in light of the ethical standards, originality and feasibility. The approval letter was obtained with ethical approval reference number phy/37/2019. The proposal was further evaluated by the Health Research Ethical Review Committee (HRERC) at Mekele University and approved with the expedited approval reference ERC 1325/2019. The data were collected after written informed consent was obtained from the study subjects. Codes were used and unauthorized persons didn't have access to the data to keep confidentiality. This study was conducted in accordance with the Declaration of Helsinki.

\section{Publication Consent}

Not applicable.

\section{Acknowledgments}

The authors would like to express sincere gratitude to the staff of ART clinic in Ayder comprehensive specialized hospital for their support and assistance in the provision of medical records and data collection processes. We also thank Addis Ababa University for sponsoring the research project.

\section{Author Contributions}

All authors made substantial contributions to conception and design, acquisition of data, or analysis and interpretation of 
data; took part in drafting the article or revising it critically for important intellectual content; agreed on the journal to which the article will be submitted; gave final approval of the version to be published; and agree to be accountable for all aspects of the work.

\section{Funding}

This study was funded by Addis Ababa University. The funders had no role in study design, data collection and analysis, decision to publish, or preparation of the manuscript.

\section{Disclosure}

The authors declare that they have no competing interests.

\section{References}

1. Opie J. Haematological complications of HIV infection. South Afr Med J. 2012;102(6):465-468. doi:10.7196/SAMJ.5595

2. World Health Organization. Haemoglobin Concentrations for the Diagnosis of Anaemia and Assessment of Severity. World Health Organization; 2011.

3. Cappellini MD, Motta I Anemia in clinical practice - definition and classification: does hemoglobin change with aging? Paper presented at: Seminars in hematology 2015. doi:10.1053/j.seminhematol.2015.07.006

4. McLean E, Cogswell M, Egli I, Wojdyla D, De Benoist B. Worldwide prevalence of anaemia, WHO vitamin and mineral nutrition information system, 1993-2005. Public Health Nutr. 2009;12 (4):444-454. doi:10.1017/S1368980008002401

5. Semba RD, Gray GE. Pathogenesis of anemia during human immunodeficiency virus infection. $J$ Invest Med. 2001;49(3):225-239. doi:10.2310/6650.2001.33967

6. Volberding PA, Levine AM, Dieterich D, et al. Anemia in HIV infection: clinical impact and evidence-based management strategies. Clin Infect Dis. 2004;38(10):1454-1463. doi:10.1086/ 383031

7. EPSA. National quantification of HIV/AIDS program pharmaceutical needs. July2019-June2021. 2019. Available from: https://epsa.gov. et/.../National-Quantification-report-for-HIVAIDS/.

8. Durandt C, Potgieter J, Khoosal R, et al. HIV and haematopoiesis. South Afr Med J. 2019;109(8 Supplement 1):S41-S46. doi:10.7196/ SAMJ.2019.v109i8b.13829

9. Madu AJ, Ughasoro MD. Anaemia of chronic disease: an in-depth review. Med Principles Pract. 2017;26(1):1-9. doi:10.1159/ 000452104

10. Wisaksana R, Sumantri R, Indrati AR, et al. Anemia and iron homeostasis in a cohort of HIV-infected patients in Indonesia. BMC Infect Dis. 2011;11(1):213. doi:10.1186/1471-2334-11-213

11. Melese H, Wassie MM, Woldie H, Tadesse A, Mesfin N. Anemia among adult HIV patients in Ethiopia: a hospital-based cross-sectional study. HIV/AIDS (Auckland, Nz). 2017;9:25. doi:10. 2147/HIV.S121021

12. Gedefaw L, Yemane T, Sahlemariam Z, Yilma D. Anemia and risk factors in HAART naïve and HAART experienced HIV positive persons in Southwest Ethiopia: a comparative study. PLoS One. 2013;8(8):e72202. doi:10.1371/journal.pone.0072202

13. Fekene TE, Juhar LH, Mengesha CH, Worku DK. Prevalence of cytopenias in both HAART and HAART naïve HIV infected adult patients in Ethiopia: a cross-sectional study. BMC Hematol. 2018;18 (1):8. doi:DOI:10.1186/s12878-018-0102-7
14. Rhoades RA, Bell DR. Medical Phisiology: Principles for Clinical Medicine. Lippincott Williams \& Wilkins; 2012.

15. Gunda DW, Kilonzo SB, Mpondo BC. Magnitude and correlates of moderate to severe anemia among adult HIV patients receiving first line HAART in Northwestern Tanzania: a cross sectional clinic based study. Pan Afr Med J. 2016;23:1. doi:10.11604/pamj.2016. 23.26.8268

16. Hyle EP, Dryden-Peterson S Use and impact of antiretroviral therapy for HIV infection in resource-limited settings. Available from: https:// www.uptodate.com/use-and-impact-of-antiretroviral-therapy-forHIV-infection-in-resource-limited-settings/. Accessed October 9, 2020.

17. Enawgaw B, Alem M, Addis Z, Melku M. Determination of hematological and immunological parameters among HIV positive patients taking highly active antiretroviral treatment and treatment naïve in the antiretroviral therapy clinic of Gondar University Hospital, Gondar, Northwest Ethiopia: a comparative cross-sectional study. BMC Hematol. 2014;14(1):8. doi:10.1186/2052-1839-14-8

18. Woldeamanuel GG, Wondimu DH. Prevalence of anemia before and after initiation of antiretroviral therapy among HIV infected patients at black lion specialized hospital, Addis Ababa, Ethiopia: a cross sectional study. BMC Hematol. 2018;18(1):7. doi:10.1186/s12878018-0099-y

19. Afari S, Blay E. Prevalence of haematological and serum biochemical abnormalities in hiv infected patients in Ghana, before and after antiretroviral therapy. IntJ Virol AIDS. 2018;5:039. doi:DOI:10. 23937/2469-567X/1510039

20. Deressa T, Damtie D, Workineh M, Genetu M, Melku M. Anemia and thrombocytopenia in the cohort of HIV-infected adults in northwest Ethiopia: a facility-based cross-sectional study. EJIFCC. 2018;29:1.

21. Tamir Z, Alemu J, Tsegaye A. Anemia among HIV infected individuals taking art with and without zidovudine at Addis Ababa, Ethiopia. Ethiop J Health Sci. 2018;28(1):73-82. doi:10.4314/ejhs. v28i1.9

22. Takuva S, Maskew M, Brennan AT, Sanne I, MacPhail AP, Fox MP. Anemia among HIV-infected patients initiating antiretroviral therapy in South Africa: improvement in hemoglobin regardless of degree of immunosuppression and the initiating ART regimen. $J$ Trop Med. 2013;2013:1-6. doi:10.1155/2013/162950

23. Fletcher $\mathrm{C}$ Overview of antiretroviral agents used to treat HIV. UpToDate, Mitty J 2016. Available from: https://www.uptodate. com/overview-of-antiretroviral-agents-used-to-treat-HIV/. Accessed October 9, 2020.

24. Zerihun KW, Bikis GA, Muhammad EA. Prevalence and associated factors of anemia among adult human immune deficiency virus positive patients on antiretroviral therapy at Debre tabor Hospital, Northwest Ethiopia. BMC Res Notes. 2019;12(1):168. doi:10.1186/ s13104-019-4214-3

25. Kathuria S, Bagga PK, Malhotra S. Peripheral hematological manifestations in HIV infected patients and correlation with CD4 counts and anti retroviral therapy. $J$ Contemporary Med Res. 2016;3 (12):3495-3498. doi:10.18203/2349-3933.ijam20191476

26. Hall JE. Guyton and Hall Textbook of Medical Physiology e-Book. Elsevier Health Sciences; 2015.

27. Dash KR, Meher LK, Hui P, Behera S, Nayak S. High incidence of zidovudine induced anemia in HIV infected patients in Southern Odisha. Ind J Hematol Blood Transfusion. 2015;31(2):247-250. doi:10.1007/s12288-014-0426-9

28. Bartlett JG, Sax PE Overview of prevention of opportunistic infections in HIV-infected patients. UpToDate; 2018.

29. Watera C, Todd J, Mutonyi G, et al. Effects of cotrimoxazole on hematologic parameters in HIV-infected adults in a community-based clinic in Entebbe, Uganda. JAIDS $J$ Acquir Immun Def Syndr. 2007;46(3):369-371. doi:10.1097/INF.0b013e $31825 \mathrm{c} 124 \mathrm{a}$ 
30. Thomas CF Jr, Limper AH Treatment and prevention of Pneumocystis pneumonia in HIV-uninfected patients. consultado 2017 dez 05. Disponível em: https://www. uptodate. com/contents/ treatmentand-prevention-of-pneumocystis-pneumonia-in-hivuninfected-patients. Accessed October 9, 2020.

31. May DB, Hooper D. Trimethoprim-Sulfamethoxazole: An Overview. Waltham, MA; 2017. Available from: www.uptodate.com/trimetho prim-sulfamethoxazole-an/overview/. Accessed October 9, 2020.
32. Alderman H, Linnemayr S. Anemia in low-income countries is unlikely to be addressed by economic development without additional programs. Food Nutr Bull. 2009;30(3):265-269. doi:10.1177/156482650903000308

33. Pasricha S-R, Drakesmith H, Black J, Hipgrave D, Biggs B-A. Control of iron deficiency anemia in low-and middle-income countries. Blood. 2013;121(14):2607-2617. doi:10.1182/blood2012-09-453522

\section{Publish your work in this journal}

The Journal of Blood Medicine is an international, peer-reviewed open access, online journal publishing laboratory, experimental and clinical aspects of all aspect pertaining to blood based medicine including but not limited to: Transfusion Medicine; Blood collection, Donor issues, Transmittable diseases, and Blood banking logistics; Immunohematology; Artificial and alternative blood based therapeutics; Hematology; Biotechnology/nanotechnology of blood related medicine; Legal aspects of blood medicine; Historical perspectives. The manuscript management system is completely online and includes a very quick and fair peer-review system. Visit http://www.dovepress.com/testimonials.php to read real quotes from published authors. 